\title{
Oxidation and Electrochemical Behavior of Monolayer- Graphene-Coated Copper in Simulated Primary Water
}

\author{
Hong-Liang Ming ${ }^{1} \cdot$ Si-Yan Wang $^{1} \cdot$ Zhi-Ming Zhang $^{1} \cdot$ Jian-Qiu Wang $^{1} \cdot$ En-Hou Han $^{1} \cdot$ Wei Ke $^{1}$
}

Received: 28 August 2015/Revised: 1 December 2015/Published online: 9 January 2016

(C) The Chinese Society for Metals and Springer-Verlag Berlin Heidelberg 2016

\begin{abstract}
In high-temperature and high-pressure water, traditional anticorrosion approaches are not suitable to be used to protect structural materials from oxidation and corrosion. In this study, monolayer graphene was explored as a barrier to protect the materials from degradation. The oxidation and corrosion rate of the monolayer-graphene-coated copper is much lower than that of the bare copper, suggesting that the monolayer graphene can effectively protect the copper from oxidation and corrosion in the simulated primary water of pressurized water reactors.
\end{abstract}

\section{KEY WORDS: Monolayer graphene; Oxidation behavior; Electrochemical behavior; Simulated primary} water

\section{Introduction}

In high-temperature pressurized water, such as in the pressurized water reactors (PWR), oxide products play a crucial role in stress corrosion cracking of the key metallic components during service [1-3]. In addition, the heat transfer efficiency of the tubes used in fabricating steam generators can be decreased by the oxide films on their surfaces, which correspondingly decreases the efficiency of electricity generation of nuclear power plants. However, unfortunately, traditional anticorrosion approaches are not suitable to be applied to protect these materials from oxidation and corrosion as the traditional coatings are not stable in high-temperature ( $\sim 290$ to $\sim 330{ }^{\circ} \mathrm{C}$ ) and highpressure $(\sim 15.5 \mathrm{MPa})$ water or as they are adverse in

Available online at http://link.springer.com/journal/40195

Jian-Qiu Wang

wangjianqiu@imr.ac.cn

1 Key Laboratory of Nuclear Materials and Safety Assessment, Liaoning Key Laboratory for Safety and Assessment Technique of Nuclear Materials, Institute of Metal Research, Chinese Academy of Sciences, Shenyang 110016, China controlling the water chemistry of the primary water and the secondary water.

Graphene, as the thinnest known material, has been widely studied across the world. Up to now, many researchers have proved that the graphene can act as an antioxidation and anticorrosion barrier under a variety of conditions where other materials would undergo rapid chemical reactions [4-12]. For instance, Kirkland et al. [4] found that graphene could effectively reduce the corrosion rate of nickel and copper when they were exposed to $0.1 \mathrm{~mol} /$ $\mathrm{L} \mathrm{NaCl}$ solution. Chen et al. [8]. found that the surfaces of $\mathrm{Cu}$ and $\mathrm{Cu} / \mathrm{Ni}$ alloys were well protected by the coated graphene even when they were heated at $200{ }^{\circ} \mathrm{C}$ in air for up to $4 \mathrm{~h}$.

Many properties of graphene, such as, can provide physical separation between substrate and reactants, chemically inert and stable in harsh environments, have determined it may have the potential to be a good antioxidation barrier in PWRs. What's more, our previous study has shown the perfect performance of the multilayer graphene to protect the nickel from oxidation in simulated primary water of PWRs [13]. Recently, the transferred monolayer graphene was also found that it could be a protective barrier for nickel-based 690 alloy in high-temperature and high-pressure water [14]. 
Though high-quality monolayer graphene is difficult to be synthesized on structural materials (e.g., stainless steels, nickel-based alloys and low alloy steels) used in PWRs, the technique to deposit high-quality monolayer graphene on pure copper is mature. As a result, monolayer-graphenecoated copper was used in this experiment. It is also important to note that cooper is not used to fabricate any part of component in the primary loop of PWRs. The main purpose is to explore the usage of the monolayer graphene to protect the metallic materials from oxidation/corrosion in simulated primary water of PWRs.

\section{Materials and Methods}

Low-pressure chemical vapor deposition (LPCVD) was used to synthesize the monolayer graphene, and the brief process was: a copper foil with a thickness of $25 \mu \mathrm{m}$ (Alfa Aesar, $99.8 \%$ ) was annealed under a hydrogen flow at $1000{ }^{\circ} \mathrm{C}$ for $30 \mathrm{~min}$, and then it was exposed to a mixture of hydrogen and methane at a total pressure of $50 \mathrm{~Pa}$ for another $30 \mathrm{~min}$ before it was cooled down to room temperature.

Then both the graphene-coated copper $(\mathrm{G} / \mathrm{Cu})$ sample and the bare copper $(\mathrm{Cu})$ sample were immersed in simulated primary water of PWRs containing $1500 \mathrm{ppm}$ (by weight) $\mathrm{B}$ as $\mathrm{H}_{3} \mathrm{BO}_{3}$ and $2.3 \mathrm{ppm}$ (by weight) $\mathrm{Li}$ as $\mathrm{LiOH} \cdot \mathrm{H}_{2} \mathrm{O}$. The immersion test was performed in a $1.4 \mathrm{~L}$ $316 \mathrm{~L}$-type autoclave at $300{ }^{\circ} \mathrm{C}$ for $250 \mathrm{~h}$. Before elevating the temperature, the simulated primary water was deaerated by high pure nitrogen gas $(99.99 \%)$ for $4 \mathrm{~h}$ at $70{ }^{\circ} \mathrm{C}$. The $\mathrm{Cu}$ and $\mathrm{G} / \mathrm{Cu}$ samples were characterized by scanning electron microscopy (SEM, FEI XL30), Raman spectroscopy (Jobin Yvon HR800) before and after immersion experiment.

The electrochemical impedance spectroscopy (EIS) was performed in the same simulated primary water in a threeelectrode cell by using 273A Potentiostat/Galvanostat (EG\&G PAR) and 5210 lock-in amplifier, while the potentiodynamic polarization was performed in the same solution by using CHI660D. The working electrode was a $\mathrm{Cu}$ or $\mathrm{G} / \mathrm{Cu}$ sample (tested area was $\sim 0.35 \mathrm{~cm}^{2}$ ), the counter electrode was a platinum foil with a surface area of $\sim 2 \mathrm{~cm}^{2}$, and the reference electrode was a saturated calomel electrode (SCE). Both the EIS and the potentiodynamic polarization were performed at room temperature. In order to get a stable open-circuit potential $\left(E_{\mathrm{ocp}}\right)$, the working electrode was immersed in the solution for $30 \mathrm{~min}$ before electrochemical measurement. The EIS tests were carried out over a frequency between $100 \mathrm{kHz}$ to $10 \mathrm{mHz}$ using a $10 \mathrm{mV}$ amplitude of sinusoidal voltage variation around the $E_{\text {ocp }}$. The scanning rate of the potentiodynamic polarization tests was $0.5 \mathrm{mV} / \mathrm{s}$.

\section{Results and Discussion}

Figure 1a shows the SEM image of the $\mathrm{G} / \mathrm{Cu}$ sample. Wrinkles or edges of the graphene are apparent. The typical Raman spectrum of the graphene on $\mathrm{Cu}$ foil with the $\mathrm{G}$ band around $1580 \mathrm{~cm}^{-1}$ and the 2D band around $2700 \mathrm{~cm}^{-1}$ is shown in Fig. 1b. D band around $1350 \mathrm{~cm}^{-1}$ reveals the defects of the graphene cannot be found, suggesting that the graphene synthesized on the $\mathrm{Cu}$ foil is in high quality [15]. The ratio of integrated intensity of the $G$ band to the $2 \mathrm{D}$ band $\left(I_{\mathrm{G}} / I_{2 \mathrm{D}}\right.$ ratio) is 0.45 , indicating that monolayer graphene is synthesized. SEM image of $\mathrm{Cu}$ sample is shown in Fig. 1c, and the rolling indentions on it are evident. The growth process of the graphene on $\mathrm{Cu}$ is self-limited, that is, once the $\mathrm{Cu}$ foil is thoroughly covered by one layer of the graphene, the growth process will be stopped because of the very low $\mathrm{C}$ solubility in $\mathrm{Cu}$ and poor $\mathrm{C}$ saturation [16]. And as a result, it is very easy to get the monolayer-graphene-coated $\mathrm{Cu}$ foil by $\mathrm{CVD}$.

Figure $2 \mathrm{a}$, b shows the SEM images of the $\mathrm{Cu}$ and $\mathrm{G} / \mathrm{Cu}$ samples after immersion experiment, respectively. Figure $2 c, d$ is higher magnification SEM images of Fig. 2a, b, respectively. Large amount of oxides can be observed on the $\mathrm{Cu}$ sample, especially at the places with the rolling indentions. However, only a few oxides can be found at the locations where the graphene has cracks on the $\mathrm{G} / \mathrm{Cu}$ sample. The cracks can provide the paths for the diffusion of the metallic ions (e.g., $\mathrm{Cu}^{2+}$ and $\mathrm{Cu}^{+}$) from the $\mathrm{Cu}$ surface to the solution/graphene interface. Once the metallic ions reach the solution/graphene interface, they will react with $\mathrm{O}^{2-}$ or $\mathrm{OH}^{-}$to form the oxides. However, evidently, no oxides can be found at the places where $\mathrm{Cu}$ substrate is covered by graphene with no cracks on the $\mathrm{G} / \mathrm{Cu}$ sample, indicating that the monolayer graphene can act as a potential antioxidation barrier in the simulated primary water.

Raman spectrum of the monolayer graphene on $\mathrm{G} / \mathrm{Cu}$ sample after immersion is shown in Fig. 3. The peak marked by $\mathrm{D}$ increases, while the peak marked by $2 \mathrm{D}$ decreases, indicating that the defects were introduced to the graphene during the immersion process. However, the monolayer graphene can act as a good barrier to protect the substrate from oxidation if it has no cracks as the oxide particles are only found at the cracks.

The anodic and cathodic polarization curves for the corrosion of $\mathrm{Cu}$ and $\mathrm{G} / \mathrm{Cu}$ samples are shown in Fig. 4a. The $E_{\text {ocp }}$ (open-circuit potential) of $\mathrm{Cu}$ and $\mathrm{G} / \mathrm{Cu}$ are very different in some published articles, and some results are even in contrast with others. Raman et al. [7] found that the $E_{\text {ocp }}$ of $\mathrm{G} / \mathrm{Cu}$ was $40 \mathrm{mV}$ more positive as compared to the bare $\mathrm{Cu}$ in $0.1 \mathrm{~mol} / \mathrm{L}$ sodium chloride $(\mathrm{NaCl})$ solution, and Prasai et al. [6] found the $E_{\text {ocp }}$ of $\mathrm{G} / \mathrm{Cu}$ was $25 \mathrm{mV}$ higher 

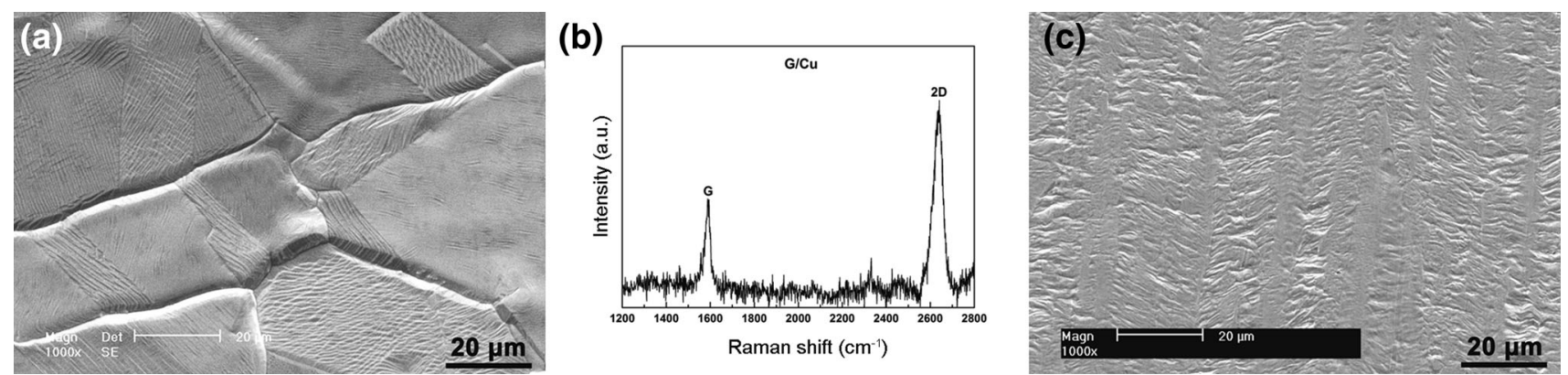

Fig. 1 SEM image of the G/Cu sample a, Raman spectrum of the graphene on the $\mathrm{G} / \mathrm{Cu}$ sample $\mathbf{b}$ and SEM image of $\mathrm{Cu}$ sample c
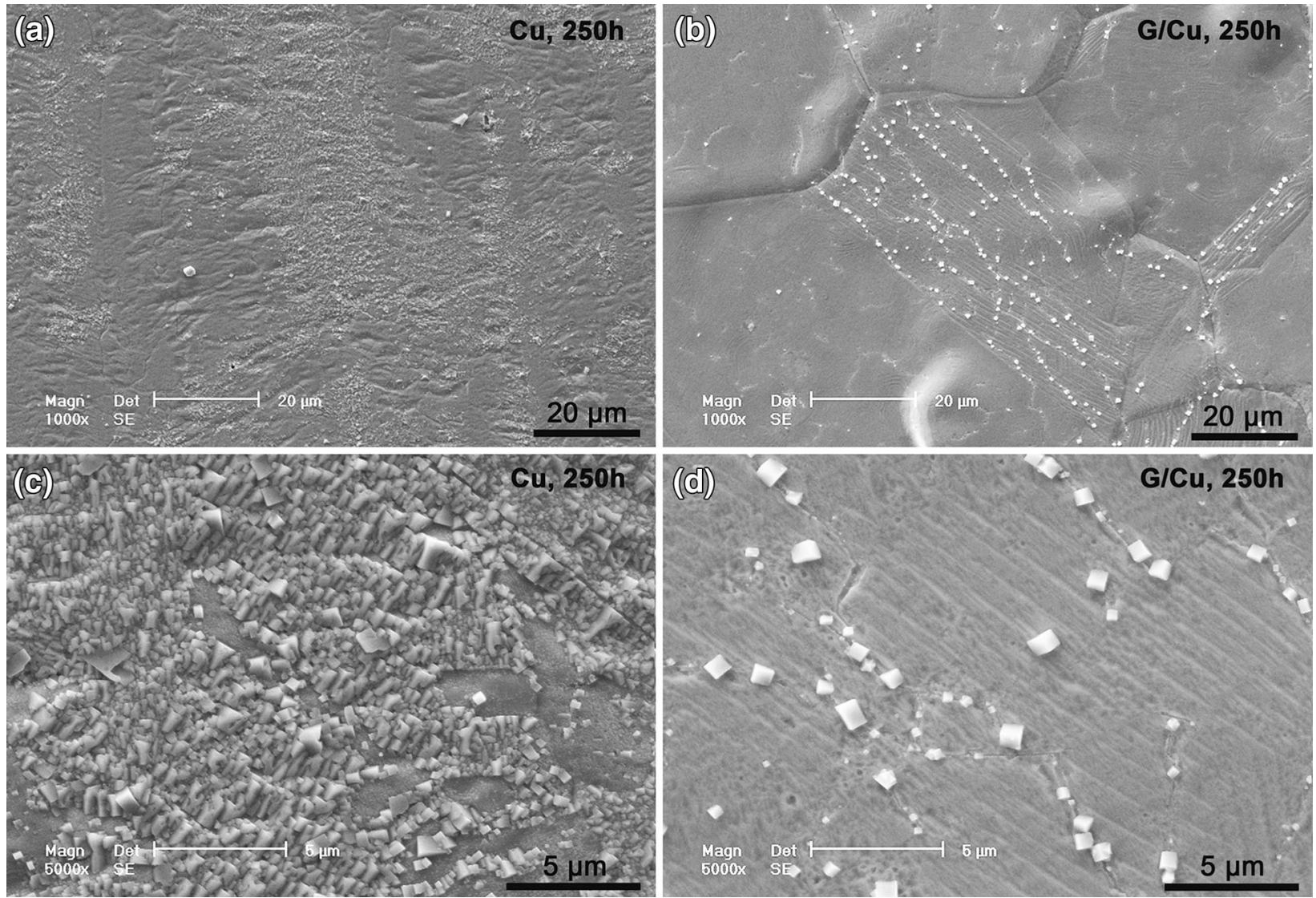

Fig. 2 SEM images of the $\mathrm{Cu}$ sample $\mathbf{a}$ and the $\mathrm{G} / \mathrm{Cu}$ sample $\mathbf{b}$ after immersion. $\mathbf{c}$ and $\mathbf{d}$ are higher magnification SEM images of $\mathbf{a}$ and $\mathbf{b}$, respectively

than $\mathrm{Cu}$ in $0.1 \mathrm{~mol} / \mathrm{L} \mathrm{Na}_{2} \mathrm{SO}_{4}$ electrolyte. However, Kirkland et al. [4] found that the $E_{\mathrm{ocp}}$ of $\mathrm{Cu}$ was $150 \mathrm{mV}$ higher than $\mathrm{Cu}$ in $0.1 \mathrm{~mol} / \mathrm{L} \mathrm{NaCl}$ solution. No matter whether the $E_{\text {ocp }, \mathrm{G} / \mathrm{Cu}}$ is higher than $E_{\mathrm{ocp}, \mathrm{Cu}}$ or not, the corrosion rate of the $\mathrm{G} / \mathrm{Cu}$ is much lower than that of the bare $\mathrm{Cu}$. So the $E_{\text {ocp }}$ is not a precise parameter to claim the corrosion rate of $\mathrm{Cu}$ and $\mathrm{G} / \mathrm{Cu}$ in these solutions even it is always the measure of corrosion susceptibility. In this research, the $E_{\text {ocp }}$ of $\mathrm{Cu}$ sample is $51 \mathrm{mV}$, about $87 \mathrm{mV}$ higher than that of the $\mathrm{G} / \mathrm{Cu}$ sample, and this also does not mean that the $\mathrm{Cu}$ sample has higher corrosion resistance as the corrosion current density $\left(i_{\text {corr }}\right)$ of $\mathrm{Cu}$ sample $\left(i_{\text {corr, } \mathrm{Cu}}=1.4 \times\right.$ $10^{-7} \mathrm{~A} / \mathrm{cm}^{2}$ ) is about four times higher than that of $\mathrm{G} / \mathrm{Cu}$ sample $\left(i_{\text {corr }, \mathrm{G} / \mathrm{Cu}}=3.3 \times 10^{-8} \mathrm{~A} / \mathrm{cm}^{2}\right)$. Corrosion rate $v_{\text {corr }}$ can be calculated from the equality $v_{\text {corr }}=i_{\text {corr }} \times$ $M_{\mathrm{Cu}} /(F \times n \times \rho)$, where $M_{\mathrm{Cu}}$ is the molecular mass for $\mathrm{Cu}, F$ is the Faraday's constant, $n$ is the stoichiometric coefficient of the electron in the electrode reaction and $\rho$ is the density of $\mathrm{Cu}$. The $v_{\text {corr }}$ of $\mathrm{G} / \mathrm{Cu}$ is four times lower than that of $\mathrm{Cu}$, suggesting that the monolayer graphene 


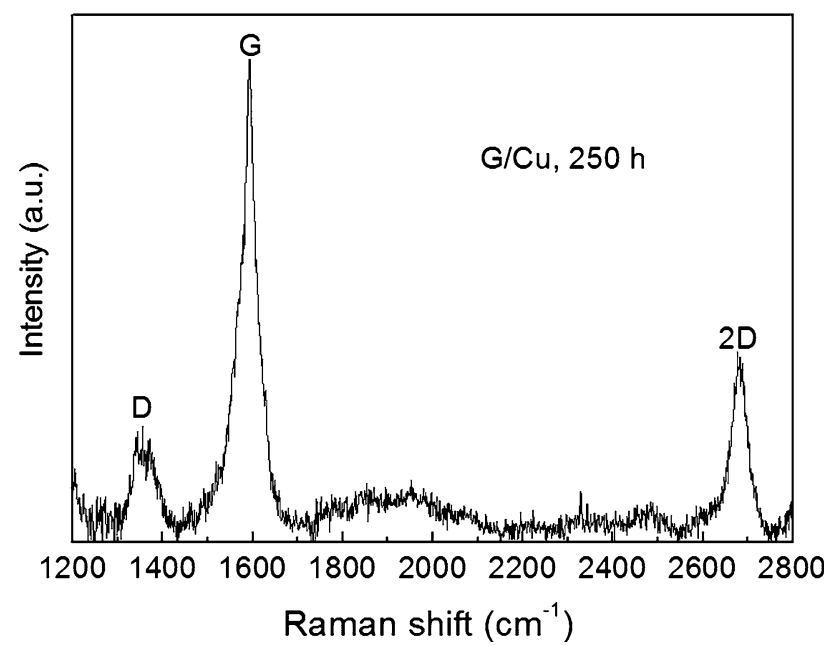

Fig. 3 Raman spectrum of the monolayer graphene on the $\mathrm{G} / \mathrm{Cu}$ sample after immersion

can significantly decrease the corrosion rate of $\mathrm{Cu}$ in the simulated primary water of PWR at room temperature.

The impedance (IZl) plots of $\mathrm{Cu}$ and $\mathrm{G} / \mathrm{Cu}$ samples are shown in Fig. 4b. When the frequency tends to be zero, the $|Z|$ tends to be $Z_{\text {real }}$ (real impedance, a measure of the corrosion resistance). The impedance of $\mathrm{G} / \mathrm{Cu}$ sample at the lowest frequency is about four times higher than that of the $\mathrm{Cu}$ sample, consistent to the relationship between the

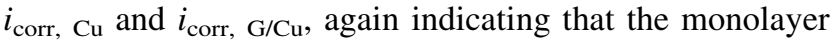
graphene can protect the $\mathrm{Cu}$ from corrosion.

As in the previous articles [5,7], $R(Q(R(C R)))$ electrical equivalent circuit was used to fit the impedance data, as shown in Fig. 5. $R_{\text {sol }}$ represents the electrolyte resistance, $C_{\mathrm{dl}}$ and $R_{\mathrm{c}}$ represent the metal/electrolyte interface, constant phase element $Q_{\mathrm{f}}$, and a pore resistance $R_{\mathrm{f}}$ represent the surface coating [7]. The values of different parameters associated with the electrical equivalent circuit are summarized in Table 1 . The values of $R_{\mathrm{sol}}, Q_{\mathrm{f}}, n, R_{\mathrm{f}}$ and $C_{\mathrm{dl}}$ of

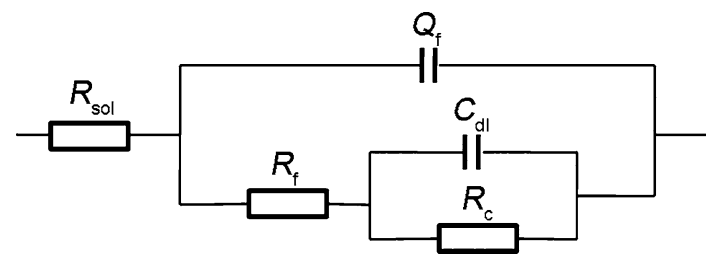

Fig. 5 Electrical equivalent circuit used to simulate the impedance data of $\mathrm{Cu}$ and $\mathrm{G} / \mathrm{Cu}$

$\mathrm{Cu}$ sample and $\mathrm{G} / \mathrm{Cu}$ sample are not much different, while $R_{\mathrm{c}}$ of the $\mathrm{G} / \mathrm{Cu}$ sample is about four times higher than that of the bare $\mathrm{Cu}$. The corrosion resistance is the mathematical sum of $R_{\mathrm{f}}$ and $R_{\mathrm{c}}$ [7], so the corrosion resistance of $\mathrm{G} / \mathrm{Cu}$ is higher than the bare $\mathrm{Cu}$.

Another aspect to evaluate the coatings is the adhesion forces between the coatings and the substrate. The adhesion energy of the monolayer graphene to $\mathrm{Cu}$ is $0.75 \mathrm{~J} / \mathrm{m}^{2}$ obtained by using atomic force microscopy with a microsphere tip [17]. And the adhesion energy is about two times higher than the transferred monolayer graphene. According to our experiment, after $500 \mathrm{~h}$ immersion in the hightemperature and high-pressure water, the transferred monolayer graphene still stick to the 690TT alloy [14]. What's more, the monolayer has very high adhesive force as it has very high area-volume ratio, so the adhesion force between the graphene and $\mathrm{Cu}$ is enough.

Schematic diagrams (Fig. 6) are used to explain why the graphene can protect $\mathrm{Cu}$ in simulated primary water. The main reason is that the graphene can physically separate $\mathrm{Cu}$ and corrosive environment. For bare $\mathrm{Cu}$ (Fig. 6a), $\mathrm{Cu}$ atoms loose electrons to become $\mathrm{Cu}$ ions and dissolve to solution. These ions will react with $\mathrm{O}^{2-}$ or $\mathrm{OH}^{-}$to form oxides or hydroxides. However, if the $\mathrm{Cu}$ is covered by monolayer graphene (Fig. 6b), the reaction will be stopped as $\mathrm{Cu}^{2+}, \mathrm{O}^{2-}$ and $\mathrm{OH}^{-}$ions cannot pass the monolayer graphene. By creating an airtight 'balloon,' Bunch et al.

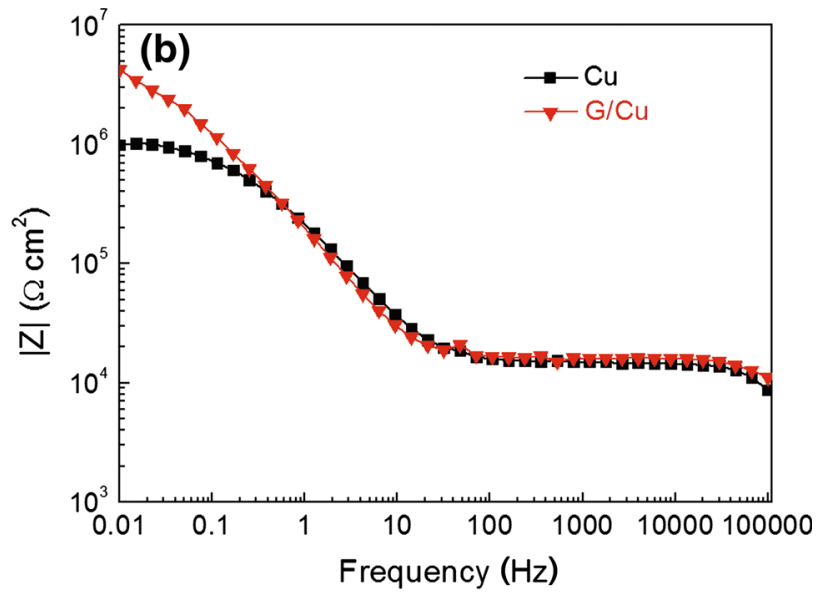

Fig. 4 Polarization curves $\mathbf{a}$ and impedance plots $\mathbf{b}$ for the $\mathrm{Cu}$ and $\mathrm{G} / \mathrm{Cu}$ samples in the simulated primary water of PWR 
Table 1 Values of different parameters associated with the electrical equivalent circuit

\begin{tabular}{llllllll}
\hline Sample & $R_{\text {sol }}\left(\Omega \mathrm{cm}^{2}\right)$ & $Q_{\mathrm{f}}\left(\mathrm{F} / \mathrm{cm}^{2}\right)$ & $n$ & $R_{\mathrm{f}}\left(\Omega \mathrm{cm}^{2}\right)$ & $C_{\mathrm{dl}}\left(\mathrm{F} / \mathrm{cm}^{2}\right)$ & $R_{\mathrm{c}}\left(\Omega \mathrm{cm}^{2}\right)$ & $\mathrm{Chi}-\mathrm{squared}$ \\
\hline $\mathrm{Cu}$ & 4736 & $2.17 \times 10^{-6}$ & 0.63 & 799 & $1.08 \times 10^{-6}$ & $4.06 \times 10^{5}$ & $2.44 \times 10^{-4}$ \\
$\mathrm{G} / \mathrm{Cu}$ & 4623 & $1.61 \times 10^{-6}$ & 0.61 & 773.4 & $1.87 \times 10^{-6}$ & $1.67 \times 10^{6}$ & $6.29 \times 10^{-4}$ \\
\hline
\end{tabular}

(a)

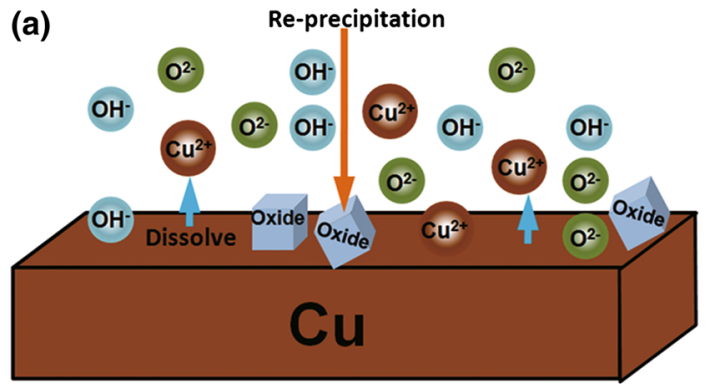

(b) Re-precipitation

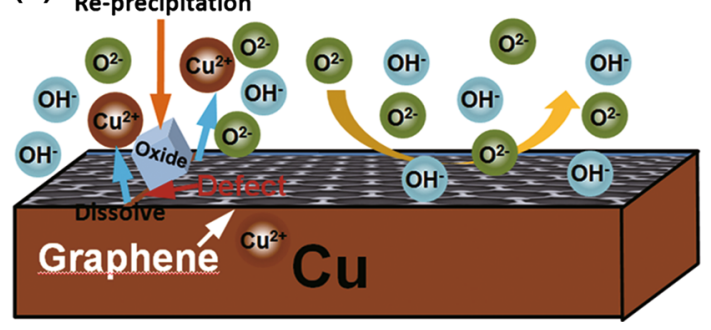

Fig. 6 Schematic diagrams used to explain why the graphene can protect $\mathrm{Cu}$ in simulated primary water: $\mathbf{a}$ bare $\mathrm{Cu}, \mathbf{b} \mathrm{G} / \mathrm{Cu}$

[18] have demonstrated that a monolayer graphene is impermeable to standard gases including helium. But, when the graphene has cracks, the cracks can provide the paths for the diffusion of metallic ions, $\mathrm{O}^{2-}$ and $\mathrm{OH}^{-}$to form oxides. The second reason is that the graphene is chemically inert and is stable in high-temperature air [8] or under conditions where other substrates will undergo rapid chemical reactions $[4,5,7]$. After immersion in the hightemperature and high-pressure water for even $1000 \mathrm{~h}$, multilayer graphene can still keep its own structure [13].

Even though the graphene can effectively protect the materials from corrosion, large-area and high-quality graphene is very difficult to be synthesized on the structural material (e.g., stainless steels and nickel-based alloys). Other approaches should be explored to coat the graphene on these materials.

\section{Conclusions}

The performance of the monolayer graphene as an antioxidation and anticorrosion barrier in the simulated primary water of PWR is studied by using the immersion experiment and the electrochemical measurement. No oxide is found at the places coated by the monolayer graphene (with no cracks), indicating that it can protect the substrate from oxidation. The corrosion rate of the graphene-coated copper is four times lower than that of the bare copper, suggesting that the monolayer graphene can protect the substrate from corrosion. In conclusion, the monolayer graphene can be a potential barrier to protect the substrate from oxidation and corrosion in PWRs.

Acknowledgments This work was financially supported by the National Basic Research Program of China (No. 2011CB610502) and the National Natural Science Fund for Distinguished Young Scholars (No. 51025104).

\section{References}

[1] T. Terachi, K. Fujii, K. Arioka, J. Nucl. Sci. Technol. 42, 225 (2005)

[2] H.L. Ming, Z.M. Zhang, S.Y. Wang, J.Q. Wang, E.H. Han, W. Ke, Mater. Corros. 66, 869 (2015)

[3] H.L. Ming, Z.M. Zhang, J.Z. Wang, R.L. Zhu, J. Ding, J.Q. Wang, E.H. Han, W. Ke, Appl. Surf. Sci. 337, 81 (2015)

[4] N.T. Kirkland, T. Schiller, N. Medhekar, N. Birbilis, Corros. Sci. 56, 1 (2012)

[5] V. Mišković-Stanković, I. Jevremović, I. Jung, K. Rhee, Carbon 75, 335 (2014)

[6] D. Prasai, J.C. Tuberquia, R.R. Harl, G.K. Jennings, B.R. Rogers, K.I. Bolotin, ACS Nano 6, 1102 (2012)

[7] R.K. Singh Raman, P. Chakraborty Banerjee, D.E. Lobo, H. Gullapalli, M. Sumandasa, A. Kumar, L. Choudhary, R. Tkacz, P.M. Ajayan, M. Majumder, Carbon 50, 4040 (2012)

[8] S. Chen, L. Brown, M. Levendorf, W. Cai, S.Y. Ju, J. Edgeworth, X. Li, C.W. Magnuson, A. Velamakanni, R.D. Piner, J. Kang, J. Park, R.S. Ruoff, ACS Nano 5, 1321 (2011)

[9] G. Kalita, M.E. Ayhan, S. Sharma, S.M. Shinde, D. Ghimire, K. Wakita, M. Umeno, M. Tanemura, Corros. Sci. 78, 183 (2014)

[10] R.K. Singh Raman, A. Tiwari, JOM 66, 637 (2014)

[11] M. Topsakal, H. Sahin, S. Ciraci, Phys. Rev. B 85, 155445 (2012)

[12] W. Zhang, S. Lee, K.L. McNear, T.F. Chung, S. Lee, K. Lee, S.A. Crist, T.L. Ratliff, Z. Zhong, Y.P. Chen, C. Yang, Sci. Rep. 4, 4097 (2014)

[13] H.L. Ming, J.Q. Wang, Z.M. Zhang, S.Y. Wang, E.H. Han, W. Ke, J. Mater. Sci. Technol. 30, 1084 (2014)

[14] H.L. Ming, S.Y. Wang, Z.M. Zhang, J.Q. Wang, E.H. Han, W. Ke, J. Mater. Sci. Technol. (2015). doi:10.1016/j.jmst.2015.11.004

[15] A.C. Ferrari, J.C. Meyer, V. Scardaci, C. Casiraghi, M. Lazzeri, F. Mauri, S. Piscanec, D. Jiang, K.S. Novoselov, S. Roth, A.K. Geim, Phys. Rev. Lett. 97, 187401 (2006)

[16] X. Li, W. Cai, J. An, S. Kim, J. Nah, D. Yang, R.S. Ruoff, Science 324, 1312 (2009)

[17] T. Jiang, Y. Zhu, Nanoscale 7, 10760 (2015)

[18] J.S. Bunch, S.S. Verbridge, J.S. Alden, A.M. van der Zande, J.M. Parpia, H.G. Craighead, P.L. McEuen, Nano Lett. 8, 2458 (2008) 